\title{
A EFICIÊNCIA FINANCEIRA E ESPORTIVA DOS MAIORES CLUBES DE FUTEBOL EUROPEUS UTILIZANDO A ANÁLISE ENVOLTÓRIA DE DADOS
}

\author{
FINANCIAL AND SPORTS EFFICIENCY OF THE GREATEST EUROPEANS \\ FOOTBALL CLUBS USING ENVELOPMENT DATA ANALYSIS
}

\author{
Marke Geisy da Silva Dantas ${ }^{a}$; Diego Rodrigues Boente ${ }^{b}$ \\ ${ }^{a}$ Graduação em Ciências Contábeis pela Universidade Federal do Rio Grande do Norte, UFRN; \\ Natal, RN - Brasil; E-mail: markegeisy@hotmail.com \\ ${ }^{b}$ Professor Assistente da Universidade Federal do Rio Grande do Norte, UFRN; \\ Mestrado em Contabilidade pela UNB/UFPB/UFRN; Natal, RN - Brasil; \\ E-mail: diegoboente@gmail.com
}

\begin{abstract}
Resumo
Os usuários das informações contábeis dos clubes de futebol geralmente buscam ter o conhecimento se os gastos despendidos por essas entidades geraram um bom desempenho esportivo durante aquela temporada e, consequentemente, na geração de receitas. Esta pesquisa tem como objetivo analisar a eficiência das despesas operacionais dos maiores clubes de futebol mundial de acordo com dois rankings: o da Revista Forbes e da empresa de auditoria Deloitte. Esta análise da eficiência foi dividida em duas partes: no aspecto financeiro e no aspecto esportivo. Para isso, foi utilizada a Análise Envoltória de Dados, que visa medir a eficiência de um conjunto de Unidades Tomadoras de Decisão que utilizam o mesmo número de Inputs e Outputs para tal fim. No tocante aos procedimentos metodológicos essa pesquisa se constitui de um estudo exploratório, pois há poucas contribuições que unem DEA e setor esportivo. O modelo de DEA utilizado foi o $\mathrm{BCC}$, orientado à Output. Os dados foram coletados nos dois rankings supracitados (despesas, receitas e o valor da entidade) e em sites que possuíam a classificação destes clubes nos campeonatos disputados na temporada 2008/2009. Os resultados demonstraram que o Manchester United e o Werder Bremen foram os clubes mais eficientes na geração de receitas. O clube Inglês também foi eficiente na geração de valor, como também no aspecto esportivo, este último junto com o Barcelona.
\end{abstract}

Palavras-chave: DEA, Clubes, Eficiência.

\begin{abstract}
The users of accounting information of football clubs usually seek to know if the expenses generated by these entities generated a good sports performance during that sports season and consequently the generation of revenue. This research aims to analyze the efficiency of the operating expenses of the biggest football clubs of the world according to two rankings: Forbes Magazine and the auditing firm Deloitte's magazine. This efficiency analysis was divided into two parts: on the financial aspect and on thesporting aspect. In order to do this, we used the Data Envelopment Analysis, which aims to measure the efficiency of a set of decision making units which take the same number of inputs and outputs for this purpose. Concerning the methodological procedures, this research is an exploratory study, because there are few contributions that join the DEA and the sports sector. The DEA model used was the BCC outputoriented. Data were collected from the two rankings mentioned above (expenditure, revenue and value of the entity) and from sites that had the sort of club championships played in the 2008/2009 season. The results showed that Manchester United and Werder Bremen clubs were more efficient in revenue generation. The English club was also efficient in generating value, but the sporting aspect, the latter along with Barcelona.
\end{abstract}

Keywords: DEA, Clubs, Efficiency. 


\section{INTRODUÇÃO}

De todos os esportes, o futebol é o esporte que mais atrai a atenção do público em todo o mundo. As grandes contratações, contratos de patrocínios, arrecadação de bilheteria etc.,que envolvem milhares de dólares são alvo de discussões tanto na mídia esportiva, quanto na população em geral.

Segundo Silva (2006, p. 7) "o esporte mundial movimenta cerca de US\$ 1 trilhão por ano". Entretanto, existe o fato de que o mercado do futebol é movido mais pelo lado da paixão do que o da razão, já que a maioria dos torcedores não se importa com os gastos e arrecadação de receitas, e sim com os títulos e as contratações de jogadores. "A gestão do futebol apresenta características que diferem das demais atividades, principalmente porque o fator psicológicoemocional está presente nas decisões e leva os gestores a tomá-las considerando a emoção em detrimento da razão" (REZENDE e PEREIRA, 2005, p. 1).

O futebol já foi um esporte que era jogado e dirigido apenas por amadores, que não visavam à obtenção de lucro. Com o passar dos anos, conforme Leoncini (2001, apud SANTOS e GREUEL, 2010) se percebe que diversas são as transformações sociais que tem ocorrido no ambiente dos clubes de futebol.

Hoje, esse esporte parece estar se transformando de uma organização baseada em valores e tradições para uma organização que enfatiza critérios de eficiência, rentabilidade e competitividade (RODRIGUES e SILVA, 2009). Porém, o futebol é um setor singular da economia devido a um dilema: é mais importante maximizar os lucros/receitas ou maximizar os títulos? Não se deve esquecer que os clubes disputam títulos e, assim sendo, a gestão estratégica do clube de futebol procura gerir de forma eficaz os recursos, para obter a maximização das receitas e o controle de custos simultaneamente à obtenção de títulos (PEREIRA et al, 2004).

Os clubes de futebol investem abundantes recursos na contratação de jogadores, com o objetivo de: arrecadar receitas e conquistar títulos. Os jogadores são os principais ativos das entidades desportivas, e a partir deles que estas entidades conseguem os seus objetivos.

A partir do sucesso dos jogadores, o clube passa a arrecadar mais com bilheteria, com patrocínios e direitos televisivos. E quanto mais essa equipe conquista vitórias, mais chances ela tem de conquistar títulos. Mas, será que os clubes são eficientes em seus gastos? O mercado do futebol tem um risco intangível considerável em relação a outros setores da economia. Talvez, em alguns casos, o clube mesmo não ganhando títulos foi eficiente nos seus gastos despendidos, de acordo com o montante do mesmo. Muitas vezes, os usuários das informações financeiras destes clubes não tem o entendimento que, apesar do clube não ter conquistado títulos, aquele gasto incorrido na temporada foi satisfatório no tocante a geração de receitas.

Com todas as mudanças de mercado que este esporte sofreu ao longo dos anos, surgiu a necessidade de se obter um maior conhecimento sobre as finanças dos principais clubes de um país, ou de todo mundo.

Inúmeros meios de Comunicação e empresas de auditoria publicam anualmente rankings dos clubes mais rentáveis, como por exemplo, o Forbes Most Valuable Soccer Teams, da Revista Americana Forbes, e o Delloite Football Money League da empresa de Auditoria Delloite. 
Além disso, existem inúmeras formas de medir a eficiência dos gastos ou qualquer outro indicador financeiro por meio de fórmulas matemáticas e métodos estatísticos. Diante de todo o exposto, a pesquisa em questão busca responder o seguinte questionamento: qual o nível de eficiência dos clubes de futebol, utilizando a análise envoltória de dados?

O objetivo geral desta pesquisa é medir a eficiência dos clubes de futebol por meio da Análise Envoltória de Dados. Com o fim de alcançar o objetivo geral proposto, são traçados os seguintes objetivos específicos:

- Discutir os principais estudos sobre o mercado do futebol brasileiro nas duas últimas décadas.

- Revisar os principais conceitos de eficiência no setor esportivo.

- Caracterizar os conceitos relacionados com o método da Análise Envoltória de Dados.

- Analisar a eficiência financeira e esportiva das entidades objetos de estudo no ano de 2009.

Os métodos estatísticos podem avaliar o desempenho de uma empresa. A Análise Envoltória de Dados (do inglês Data Envelopment Analysis - DEA) é uma técnica que visa medir a eficiência de um determinado número de Unidades Tomadoras de Decisão (do inglês Decision Making Units, DMU) semelhantes que utilizam os mesmos insumos (inputs) geradores dos mesmos produtos (outputs).

\section{REFERENCIAL TEÓRICO}

\subsection{O mercado do futebol}

O futebol deixou de ser uma atividade que envolve apenas a paixão do torcedor pelo seu clube, se transformando em uma grande indústria de entretenimento onde circula bilhões de dólares por ano.

A partir da década de 80, após a consolidação do capitalismo como sistema político e econômico hegemônico, em conjunto com a evolução da mídia e meios de transmissão eletrônicos, foi agregado ao esporte o paradigma mercadológico, com possibilidades ilimitadas do ponto de vista econômico (PERRUCI, 2006).

O futebol começou a ser tratado como negócio a partir do momento que a televisão passou a exibir os jogos gratuitamente, e assim dar origem aos patrocinadores, tanto nas placas publicitárias, como nas camisas das equipes.

A evolução do sistema de receitas na indústria do futebol pode ser dividida em quatro partes, segundo Ekelund (1998, apud SILVA e CAMPOS FILHO, 2006, p. 198):

- Até a década de 50 (A Era do Estádio), onde a principal receita do negócio era a relação clube - torcedor com a venda das entradas nos estádios;

- Entre as décadas de 50 - 70 (A Era da TV Comercial Tradicional), quando as televisões passaram a transmitir os jogos e originaram os patrocinadores;

- Década de 80 (A Era dos Patrocinadores), quando os patrocinadores passaram a se interessar pelo futebol pela visibilidade proporcionada pelo aumento da audiência e estampando suas marcas nas camisas das equipes; e, 
- Após a década de 80 (A era da Nova Mídia), quando a televisão e a internet passaram a ser grandes consumidores (intermediários), pagando pelos direitos de transmissão com objetivo de retorno financeiro.

Ou seja, antes as organizações desportivas apenas possuíam uma única fonte de receita que era o ingresso comprado por seus torcedores. Hoje, com a televisão, a internet e advento das mídias sociais os clubes também arrecadam com os direitos cedidos para a utilização da sua marca nestes meios de comunicação.

Obviamente, as receitas dos clubes de futebol não se restringem apenas a estas supracitadas. A venda de direitos federativos de jogadores (principalmente oriundos dos países da América do Sul e da África), a venda de produtos licenciados com o distintivo do time, e, em alguns casos a utilização da arena esportiva por terceiros são importantes receitas para as equipes, e em muitos casos são as principais. Além disso, existe outra fonte de receitas: o mercado acionário. De acordo com Dantas et al (2009) existem em todo o mundo 38 entidades desportivas que abriram seu capital para negociação em bolsas de valores.

O primeiro clube de futebol a abrir o capital em bolsa de valores foi o Tottenham Hottspur, em 1983, captando 9,2 milhões de libras. Porém, o principal exemplo de sucesso em entidades desportivas com o capital aberto é o Manchester United. O Manchester United foi o segundo clube inglês a lançar ações na Bolsa de Valores (em 1991) tornando-se assim uma empresa de capital aberto.

Ao contrário dos outros setores da economia, que basicamente são movidos pela lei da oferta e da procura, o futebol é mais movido pela paixão (principalmente de seus torcedores) do que pela razão.

O principal ativo de uma entidade desportiva são os seus atletas. São com eles que o clube atinge suas metas, tanto financeiras quanto esportivas. Quanto maior a qualidade desses jogadores maior será a visibilidade do clube, porque são estes jogadores que atraem o público aos estádios, patrocínios e a mídia em geral. Obviamente, também quanto maior for a qualidade destes jogadores, maior será a probabilidade do clube conquistar títulos. E na conquista destes títulos é que o clube passa também a arrecadar mais.

Basicamente existe um ciclo nos gastos pertinentes à atividade do futebol. Com os recursos oriundos dos vários tipos de receitas, como patrocínios, bilheteria, direitos televisivos etc., são contratados os jogadores e pagos os seus salários. Quanto maior o recurso gasto, maior é a probabilidade de contratação de grandes jogadores. Portanto, o ciclo se estabelece. Os recursos são investidos nos melhores jogadores possíveis para aquele montante destinado, com estes, o clube tem mais capacidade de conquistar títulos, e com estes títulos, passa a gerar mais recursos.

Contudo, o mercado do futebol não se comporta dessa forma. Existe um risco considerável no setor, pois os ativos em questão são seres humanos. Ao contrário de máquinas que com quase certeza, a não ser que ocorra algo extraordinário, fabricam uma quantidade $\mathrm{X}$ de produtos em determinado tempo, no futebol nunca se pode afirmar com exatidão se algum investimento logrará êxito. Na história do esporte, existem alguns casos de equipes montadas com grandes investimentos, mas não conseguiram atingir os seus objetivos.

Por isso, os gestores das entidades desportivas devem se adequar as premissas deste mercado singular. Primeiramente, os investimentos devem estar de acordo com as condições financeiras do clube. Depois, devem-se achar maneiras para, em caso de o clube não estar bem esportivamente mesmo com jogadores de qualidade, atrair novos recursos, como ações de marketing, exploração de imagem de algum jogador, etc. 
A observação da eficiência dos gastos dos clubes só se dará com organização financeira aliada com o bom trabalho do clube dentro de campo. Somente essa dualidade que torna um clube de futebol um negócio rentável.

\subsection{Análise Envoltória de Dados}

Eficiência é a maneira utilizada para atingir determinado objetivo/meta. A eficiência compara o que foi produzido, dado os recursos disponíveis, com o que poderia ter sido produzido com os mesmos recursos.

A Análise Envoltória de Dados é um método matemático não-paramétrico introduzido por Charnes, Cooper e Rhodes (1978) e estendida por Banker, Charnes e Cooper (1984), que avalia a eficiência de determinado conjunto de Unidades Tomadoras de Decisão (ou DMU) que se utiliza de insumos para gerar produtos, sendo insumos e produtos em comum entre ambas. Ou seja, o quanto uma DMU pode extrair de produtos com determinada quantidade de insumos. Além disso, existe a possibilidade de considerar variáveis que não estejam ligadas ao aspecto financeiro.

A DEA representa uma estrutura formada por unidades de decisão com entradas e saídas definidas de forma a avaliar a eficiência relativa das mesmas. Essa eficiência é definida a partir do desempenho observado das DMU nas variáveis analisadas, sendo uma medida empírica, e, não, uma referência teórica ou conceitual (GONÇALVES et al, 2007).

Este método calcula um índice de eficiência que poderá ter valores de zero a um. Quanto mais perto de um, mais ela será eficiente do que as outras DMUs, e obviamente a unidade que conseguir o índice um será considerada eficiente com aquela quantidade de insumos (inputs) e produtos (outputs). A partir do cálculo desse índice, é formada uma linha (ou fronteira) com as DMUs que obtiveram índice um, e abaixo desta fronteira, será formada uma região com a marcação dos índices das DMUs não-eficientes, conforme a Figura 1:

Figura 1: Fronteira Eficiente - Y: Produtos; X: Insumos

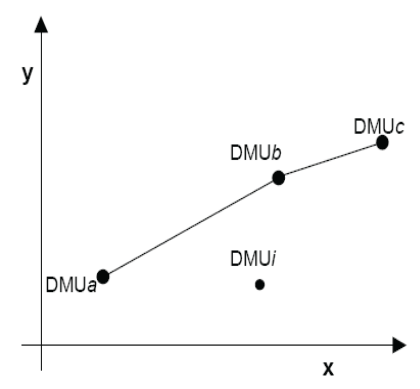

Fonte: Borges (2006, p, 5)

O sucesso da técnica DEA deve-se a suas poucas hipóteses, que permite sua aplicação em casos que tem sido resistente a outras pesquisas por causa da complexidade e do frequente desconhecimento da natureza das relações entre múltiplos inputs e outputs (LAMERA, FIGUEIREDO \& ZAVALA, 2008).

O DEA é conhecido por seus modelos. Melo et al (2008) relata que são dois os principais modelos DEA: Modelo CCR, desenvolvido por Charnes, Cooper e Rhodes em 1978, tem por 
principal característica permitir uma avaliação objetiva da eficiência global e identificar as fontes de ineficiência; e Modelo BCC, que teve origem em 1984, criado por Banker, Charnes e Cooper, apresentado o diferencial de permitir a distinção entre ineficiências técnicas e de escala, identificando a presença de ganhos de escala crescente, decrescente e constante.

O modelo Constant Returns to Scale - CRS, chamado também de CCR (de Charnes, Cooper e Rhodes) mostra que, segundo Gonçalves et al (2007), no caso de uma unidade com um único par entrada - saída, a eficiência da unidade pode ser definida simplesmente como a razão saída/entrada. No caso de várias entradas e/ou saídas, a eficiência é a razão entre a soma ponderada das saídas e a soma ponderada das entradas. Já o modelo BCC (de Banker, Charnes e Cooper) forma uma fronteira com várias unidades eficientes, formado uma espécie de envelope entre as unidades ineficientes. Este modelo passa a considerar DMUs com menores insumos e menores consumos, que de acordo com sua produtividade passam a serem unidades eficientes. Estas unidades no modelo CCR não seriam consideradas com a eficiência total. O modelo BCC compara unidades de portes distintos.

Figura 2: Formulação do modelo CCR e BCC

$$
\begin{array}{ll}
\text { Maximizar : } h_{0}=\sum_{y=1}^{s} v_{y} O_{y 0} ; & \text { Maximizar } h_{0}=\sum_{y=1}^{s} v_{y} O_{y 0}+v_{0} ; \text { sujeito à: } \\
\text { sujeito à : } \sum_{x=1}^{r} u_{x} I_{x 0}=1 ; & \sum_{x=1}^{r} u_{x} I_{x 0}=1 ; \\
\sum_{y=1}^{s} v_{y} O_{y k} \cdot \sum_{x=1}^{r} u_{x} I_{x k} \leq 0, \mathrm{k}=1,2,3, \ldots, \mathrm{n} ; & \sum_{y=1}^{s} v_{y} O_{y k} \cdot \sum_{x=1}^{r} u_{x} I_{x k}+v_{0} \leq 0, \mathrm{k}=1,2,3, \ldots, \mathrm{n} ; \\
u_{x}, v_{y} \geq 0, \forall \mathrm{x}, \mathrm{y} & u_{x}, v_{y} \geq 0, \forall \mathrm{x}, \mathrm{y} \\
& v_{0} \text { Irrestrito. }
\end{array}
$$

Fonte: Silva e Azevedo (2004, p. 80 e p.81)

Em que:

h0 $=$ Eficiência relativa à DMU 0;

$\mathrm{n}=$ número de unidades (Total de DMUs);

$\mathrm{s}=$ número de outputs;

$\mathrm{r}=$ número de inputs;

I xk = Quantidade do input x para a DMU k; $\mathrm{k}=1,2, \ldots, \mathrm{n}$;

O yk = Quantidade do output y para a DMU k; k=1,2,..,n;

$\mathrm{u} \mathrm{x}=$ Peso designado ao input $\mathrm{x}$;

$\mathrm{v} y=$ Peso designado ao output $\mathrm{y}$.

A única diferença entre os dois modelos é a adição de v0. A variável v 0 no problema informa se os retornos de escala são constantes, crescentes ou decrescentes para a projeção ótima. Se v0 assumir um valor não-negativo, a produção é caracterizada por um retorno de escala crescente. Se v0 assumir um valor negativo, a produção é caracterizada por um retorno 
de escala decrescente. Se v0 for igual a zero, diz-se que a produção é caracterizada por um retorno de escala constante (SILVA e AZEVEDO, 2004). A figura 8 demonstra um gráfico com os dois modelos:

Figura 3: Representação das fronteiras CCR e BCC.

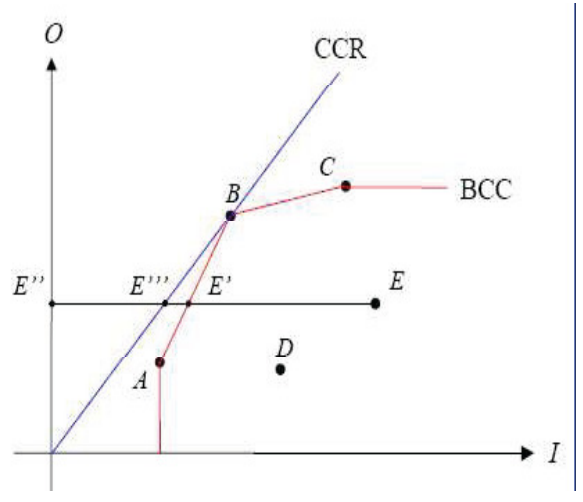

Fonte: Mello et al (2005, p, 2.534)

Segundo Jamasb e Pollitt (2002), os modelos DEA podem ser orientados a inputs e outputs e podem ser especificados como uma escala constante de retorno (CRS) ou retornos de escala variáveis (VRS). Modelos de orientação à outputs maximizam os mesmos para uma determinada soma de fatores de input. No inverso, os modelos de orientação à inputs minimizam os fatores de input requeridos para determinado nível de output.

\section{METODOLOGIA}

A tipologia desta pesquisa quanto aos seus objetivos se caracteriza pelo caráter exploratório. Conforme Raupp e Beuren (2009, p. 80) esta caracterização ocorre quando "há pouco conhecimento sobre a temática a ser abordada". Quanto aos procedimentos utilizados, esta pesquisa se caracteriza como uma Pesquisa Documental. Também se caracteriza por ser uma pesquisa bibliográfica, pois se baseia na bibliografia pública sobre determinado assunto em qualquer tipo de publicação escrita, falada ou filmada.

Quanto à abordagem do problema, este estudo segue tanto a tipologia de pesquisa quantitativa como a qualitativa.

A pesquisa em questão utiliza-se dos Rankings da temporada 08/09 da Revista Forbes (Forbes Most Valuable Soccer Teams) e da empresa de auditoria Delloite (Delloite Football Money League) referente a 20 clubes da Europa, que coincidentemente nos dois documentos são os mesmos. Foram coletados os dados referentes as receitas totais e suas divisões, e o valor do clube, para serem usados como output financeiro. O input do modelo financeiro será as despesas operacionais.

Para a eficiência esportiva o input foi obtido pela divisão entre as despesas com as receitas, sendo esta razão multiplicada por 100, para utilizá-lo como porcentagem, já que o Output da eficiência esportiva será uma porcentagem, que é o aproveitamento dos pontos.

Foram coletadas também na internet as tabelas referentes a todos os campeonatos disputados (Campeonatos nacionais, Liga dos Campeões da Europa e UEFA Europa League) por esses clubes durante a temporada estudada para o tratamento dos dados no cálculo da eficiência esportiva. 
O aproveitamento dos pontos refere-se a razão entre a quantidade de pontos conquistados e o número de pontos disputados (número de partidas x 3 pontos). Foi adotada esta metodologia devido a diferença entre o número de jogos disputados pelos clubes da amostra nos diferentes campeonatos do país.

O método DEA será o BCC (ou VRS) - Retornos Variáveis de Escala, pois se trata de entidades de portes diferentes. Além disso, o objetivo é medir qual destas entidades é a mais eficiente da amostra, para servir de benchmarking para as outras. O modelo BCC será orientado aos outputs, devido à busca pela resposta de que de acordo com os gastos despendidos com futebol, estes conseguem maximizar o ganho de receitas e a conquista dos títulos.

Os dados serão trabalhados no programa SIAD v3 ${ }^{\circledR}$ - Sistema Integrado de Apoio à Decisão. Este programa foi desenvolvido por Meza et al (2003) com o objetivo de calcular todos resultados dos modelos DEA clássicos (eficiência, pesos, alvos, benchmarks e folgas).

\section{ANÁLISE DE DADOS}

\subsection{Eficiência Financeira}

Como determinado na metodologia o único Input será as Despesas Operacionais do período para os modelos financeiro e esportivo. A eficiência financeira será medida utilizando o Output Receitas Totais. A divisão e a conseqüente medida de eficiência das receitas em Jogos, Transmissão e Comercial serão mensuradas apenas a título de ilustração.

O Valor Econômico do clube no período 08/09 também será utilizado como Output para medir a eficiência na agregação de valor das entidades estudadas. O Quadro 1 mostra estes valores retirados da Revista FORBES e do Delloite Football Money League:

Quadro 1: Variáveis utilizadas no modelo financeiro "em milhões de € (euros)".

\begin{tabular}{|c|c|c|c|c|c|c|}
\hline \multicolumn{7}{|c|}{ INPUT } \\
\hline Times & Despesas & Jogos & Transmissão & Comercial & Receitas Totais & Valor \\
\hline Man.United & 215 & 127,7 & 117,1 & 82,2 & 327 & 1380 \\
\hline Real Madrid & 304 & 101,4 & 160,8 & 139,2 & 401 & 995 \\
\hline Arsenal & 187 & 117,5 & 89,0 & 56,5 & 263 & 888 \\
\hline Barcelona & 280 & 95,5 & 158,4 & 112,0 & 365 & 752 \\
\hline Bayern Munique & 244 & 60,6 & 69,6 & 159,3 & 289 & 744 \\
\hline Liverpool & 190 & 49,9 & 87,6 & 79,5 & 217 & 618 \\
\hline Milan & 166 & 33,4 & 99,0 & 64,1 & 196 & 601 \\
\hline Juventus & 161 & 16,7 & 132,2 & 54,3 & 203 & 493 \\
\hline Chelsea & 296 & 87,4 & 92,9 & 62,0 & 242 & 486 \\
\hline Internazionale & 206 & 28,2 & 115,7 & 52,6 & 196 & 310 \\
\hline Schalke 04 & 129 & 29,2 & 34,2 & 61,1 & 124 & 288 \\
\hline Tottenham & 106 & 46,3 & 52,6 & 33,8 & 132 & 279 \\
\hline O.Lyon & 136 & 22,4 & 68,1 & 49,1 & 139 & 250 \\
\hline Hamburgo & 117 & 55,5 & 35,6 & 55,6 & 147 & 247 \\
\hline Werder Bremen & 96 & 27,8 & 61,2 & 25,7 & 114 & 206 \\
\hline Roma & 128 & 18,8 & 86,9 & 40,7 & 146 & 231 \\
\hline O. Marselha & 119 & 24,9 & 65,6 & 42,7 & 133 & 197 \\
\hline Borussia & 97 & 22,2 & 22,4 & 58,9 & 103 & 196 \\
\hline Man.City & 144 & 24,4 & 56,7 & 21,1 & 102 & 194 \\
\hline Newcastle & 137 & 34,1 & 44,1 & 22,8 & 101 & 148 \\
\hline
\end{tabular}

Fonte: Elaborado pelos Autores

A ordem dos clubes no Quadro 1 foi estabelecida de acordo com o Forbes Most Valuable 
Soccer Teams, que considera o Valor do Clube como critério. Percebe-se então que o Manchester United é o clube mais valioso da amostra, com $€ 1,38$ bi, seguido de Real Madrid, Arsenal e Barcelona.

Em relação às receitas, que o critério do Ranking da Delloite, o Real Madrid é o clube que mais arrecadou no período em análise, com $€ 401 \mathrm{mi}$, seguido por Barcelona ( $€ 365 \mathrm{mi}$ ), Manchester United ( $€ 327 \mathrm{mi}$ ) e Bayern de Munique ( $€ 289 \mathrm{mi}$ ). Com a utilização do SIAD v.3 o DEA foi calculado para se chegar à eficiência financeira. A Tabela 1 mostra os resultados:

Tabela 1: Resultados do modelo financeiro.

\begin{tabular}{c|c|c|c|c}
\hline Times & Jogos & Transmissão & Comercial & Rec. Totais \\
\hline Man.United & 1,000 & 0,814 & 0,589 & 1,000 \\
\hline Real Madrid & 0,789 & 1,000 & 0,811 & 1,000 \\
\hline Arsenal & 1,000 & 0,646 & 0,474 & 0,950 \\
\hline Barcelona & 0,750 & 1,000 & 0,704 & 0,958 \\
\hline Bayern Munique & 0,477 & 0,466 & 1,000 & 0,823 \\
\hline Liverpool & 0,420 & 0,636 & 0,654 & 0,769 \\
\hline Milan & 0,332 & 0,744 & 0,604 & 0,819 \\
\hline Juventus & 0,179 & 1,000 & 0,527 & 0,881 \\
\hline Chelsea & 0,680 & 0,581 & 0,390 & 0,614 \\
\hline Internazionale & 0,224 & 0,818 & 0,398 & 0,630 \\
\hline Schalke 04 & 0,435 & 0,350 & 0,755 & 0,716 \\
\hline Tottenham & 1,000 & 0,737 & 0,522 & 1,000 \\
\hline O.Lyon & 0,302 & 0,650 & 0,573 & 0,749 \\
\hline Hamburgo & 1,000 & 0,429 & 0,771 & 0,969 \\
\hline Werder Bremen & 1,000 & 1,000 & 1,000 & 1,000 \\
\hline Roma & 0,289 & 0,907 & 0,512 & 0,852 \\
\hline O. Marselha & 0,433 & 0,766 & 0,581 & 0,857 \\
\hline Borussia & 0,738 & 0,354 & 1,000 & 0,889 \\
\hline Man.City & 0,300 & 0,503 & 0,231 & 0,510 \\
\hline Newcastle & 0,461 & 0,416 & 0,267 & 0,539 \\
\hline
\end{tabular}

Fonte: Elaborado pelos autores

Em relação à arrecadação de jogos, os clubes que obtiveram o índice máximo de eficiência foram Manchester United, Arsenal, Tottenham, Hamburgo e Werder Bremen. É interessante de nota o fato que todos os clubes italianos da amostra estão entre os menos eficientes neste quesito, sendo a Juventus a pior de toda a amostra $(0,179)$.

Para a Receita de Transmissão em meios de comunicação destes jogos, os mais eficientes foram Real Madrid, Barcelona, Juventus e Werder Bremen. Nota-se que os clubes italianos sofreram uma melhora neste quesito em relação ao anterior, tomando como exemplo a Juventus, que obteve o índice máximo. Agora, os clubes alemães não se mostraram eficientes com este tipo de receita.

Já para as receitas comerciais, os clubes que se mostraram mais eficientes foram três clubes alemães (Bayern de Munique, Werder Bremen e Borussia). Os clubes que obtiveram os menores escores de eficiência foram ingleses, como Manchester City $(0,267)$, Newcastle $(0,267)$ e Chelsea $(0,390)$.

Percebe-se com essa análise que para cada tipo de receita, algum país não se adéqua, já que cada nação tende a se aproveitar de certo aspecto do mercado de futebol, de acordo com suas características, como assistir os jogos em casa ou no estádio, o número de torcedores 
capazes de consumir os produtos do patrocinador do clube, dentre outras.

No tocante a receita total, os clubes eficientes foram Manchester United, Real Madrid, Tottenham e Werder Bremen. Aqui, deve-se abrir um parêntese para explicar por que alguns clubes de menor expressão são eficientes em relação aos outros de maior expressão. O DEA, principalmente no modelo BCC, de retornos variáveis de escala, compara os clubes que operam na mesma escala, ou seja, aqueles que estão mais próximos em termos de características semelhantes, como despesas parecidas, etc.

O DEA também foi utilizado para medir a eficiência na geração de valor para a entidade no período estudado. $\mathrm{O}$ resultado encontra-se na Tabela:

Tabela 2: Resultado da agregação de valor

\begin{tabular}{|c|c|}
\hline Times & Valor \\
\hline Man.United & 1,000 \\
\hline Real Madrid & 0,721 \\
\hline Arsenal & 0,805 \\
\hline Barcelona & 0,545 \\
\hline Bayern Munique & 0,539 \\
\hline Liverpool & 0,545 \\
\hline Milan & 0,670 \\
\hline Juventus & 0,582 \\
\hline Chelsea & 0,352 \\
\hline Internazionale & 0,240 \\
\hline Schalke 04 & 0,542 \\
\hline Tottenham & 0,916 \\
\hline O.Lyon & 0,416 \\
\hline Hamburgo & 0,598 \\
\hline Werder Bremen & 1,000 \\
\hline Roma & 0,443 \\
\hline O. Marselha & 0,455 \\
\hline Borussia & 0,908 \\
\hline Man.City & 0,285 \\
\hline Newcastle & 0,242 \\
\hline
\end{tabular}

Fonte: Elaborado pelos autores

Os clubes que mais agregaram valor no período foram o Manchester United e o Werder Bremen, clubes que também foram eficientes no tocante a arrecadação de receitas.

\subsection{Eficiência Esportiva}

Para obter o nível de eficiência esportivo, foi utilizado o Output aproveitamento dos pontos durante o período. Porém este número está em porcentagem, e obviamente o Input deveria seguir a mesma regra. Por isso, foi determinado que o Input fosse o resultado da divisão entre as despesas e receitas, multiplicado por 100. O resultado alcançado é demonstrado no 
Quadro 2:

Quadro 2: Variáveis utilizadas no modelo esportivo.

\begin{tabular}{|c|c|c|}
\hline & INPUT & OUTPUT \\
\hline Times & \% Desp./Rec. & $\%$ Aproveitamento \\
\hline Man.United & 66 & 75 \\
\hline Real Madrid & 76 & 65 \\
\hline Arsenal & 71 & 60 \\
\hline Barcelona & 77 & 75 \\
\hline Bayern Munique & 84 & 67 \\
\hline Liverpool & 88 & 74 \\
\hline Milan & 85 & 65 \\
\hline Juventus & 79 & 63 \\
\hline Chelsea & 122 & 69 \\
\hline Internazionale & 105 & 67 \\
\hline Schalke 04 & 104 & 48 \\
\hline Tottenham & 80 & 46 \\
\hline O.Lyon & 98 & 60 \\
\hline Hamburgo & 80 & 63 \\
\hline Werder Bremen & 84 & 45 \\
\hline Roma & 88 & 54 \\
\hline O. Marselha & 89 & 59 \\
\hline Borussia & 94 & 57 \\
\hline Man.City & 141 & 49 \\
\hline Newcastle & 136 & 30 \\
\hline
\end{tabular}

Fonte: Elaborado pelos Autores

Assim, o resultado pode ser analisado da seguinte forma: Quanto menor a porcentagem, melhor foi a arrecadação de receitas em relação às despesas. Caso este número seja maior que 100 , quer dizer que as despesas sobressaíram em relação às receitas.

Pode-se perceber que o clube que mais arrecadou perante as despesas incorridas também foi o Manchester United, seguido de Arsenal, Real Madrid e Barcelona. Exatamente os clubes que mais agregaram valor na temporada 08/09. Já os clubes que tiveram resultado operacional negativo foram o Manchester City (141\%), Newcastle (136\%), Chelsea (122\%), Internazionale (105\%) e Schalke 04 (104\%).

Foram coletados a pontuação dos campeonatos nacionais de cada equipe, da Liga dos Campeões da Europa, UEFA Europa League e Mundial Interclubes, para utilizar como Output. A Tabela 3 mostra o resultado: 
A Eficiência Financeira e Esportiva dos Maiores Clubes de Futebol Europeus

Utilizando a Análise Envoltória de Dados

Tabela 3: Resultado da eficiência esportiva

\begin{tabular}{|c|c|}
\hline Times & Índice \\
\hline Man.United & 1,000 \\
\hline Real Madrid & 0,867 \\
\hline Arsenal & 0,800 \\
\hline Barcelona & 1,000 \\
\hline Bayern Munique & 0,893 \\
\hline Liverpool & 0,987 \\
\hline Milan & 0,867 \\
\hline Juventus & 0,840 \\
\hline Chelsea & 0,920 \\
\hline Internazionale & 0,893 \\
\hline Schalke 04 & 0,640 \\
\hline Tottenham & 0,613 \\
\hline O.Lyon & 0,800 \\
\hline Hamburgo & 0,840 \\
\hline Werder Bremen & 0,600 \\
\hline Roma & 0,720 \\
\hline O. Marselha & 0,787 \\
\hline Borussia & 0,760 \\
\hline Man.City & 0,653 \\
\hline Newcastle & 0,400 \\
\hline
\end{tabular}

Fonte: Elaborado pelos autores

Os clubes considerados eficientes pela metodologia DEA-BCC foram Manchester United e Barcelona, clubes que alcançaram 75\% de aproveitamento durante a temporada estudada. Além disso, estas equipes também conquistaram títulos na temporada. O Manchester foi campeão Inglês e Vice da Liga dos Campeões e o Barcelona foi campeão do Campeonato Espanhol, Liga dos Campeões e do Mundial Interclubes.

A Internazionale se tornou campeã no campeonato italiano no período não foi considerado eficiente, justamente porque a metodologia utiliza o aproveitamento dos pontos como output, que não significa conquista de títulos. Além disso, a equipe disputou também a Liga dos Campeões e não logrou êxito, assim o seu aproveitamento diminuiu em relação ao aproveitamento, como também seu índice de despesa foi de $105 \%$. O Liverpool obteve a segunda maior eficiência $(0,987)$ da amostra, com aproveitamento de $74 \%$ na pontuação e $88 \%$ de despesas em relação às receitas.

O pior clube da amostra foi o Newcastle, que gastou 36\% a mais do que arrecadou e foi rebaixado no campeonato inglês no mesmo ano. Isso corrobora com a sistemática que o desempenho esportivo dentro de campo gera receitas para o clube, ou seja, as duas eficiências são correlacionadas. 


\section{CONSIDERAÇÕES FINAIS}

A Análise Envoltória de Dados é utilizada por vários nichos da economia para medir a eficiência de determinado número de DMUs, que utilizam Inputs e Outputs semelhantes. Porém, em setores de entretenimento como o esporte, há poucas contribuições científicas.

Nesta pesquisa o DEA foi utilizado para medir a eficiência financeira e esportiva dos clubes europeus que compõem o Ranking de duas organizações que avaliam vários setores da economia: a Revista Forbes e a empresa de auditoria Deloitte.

O resultado financeiro ainda fora dividido em três tipos de receitas: de jogos, de transmissão e comercial. Na primeira os clubes considerados eficientes foram: Manchester United, Arsenal, Tottenham, Hamburgo e Werder Bremen. Na segunda, Real Madrid, Barcelona, Juventus e Werder Bremen. E para as receitas comerciais, Bayern de Munique, Werder Bremen e Borussia. No total, Manchester United e Werder Bremen alcançaram o índice máximo.

No tocante a geração de valor, apenas o Manchester United obteve o índice máximo. Para a eficiência esportiva os clubes que alcançaram $75 \%$ de aproveitamento, Manchester United e Barcelona foram considerados eficientes na temporada 08/09.

Pode-se considerar que a sistemática DEA é plausível para determinar se os clubes de futebol em determinado período foram eficientes ou não, de acordo com seus níveis de despesas, tanto no tocante da geração de receitas, quanto no desempenho esportivo, devendo sempre lembrar que o desempenho esportivo é determinante também para a geração de receitas.

\section{REFERÊNCIAS}

BANKER, R. D.; CHARNES, A.; COOPER, W. W. Some models for estimating technical and scale inefficiencies in data envelopment analysis. Management Science, v. 30, n. 9, p. 10781092, September 1984.

BORGES, Renato Sérgio. Confrontando avaliações: exame nacional de cursos e análise envoltória de dados. Intersaberes Revista Científica, Curitiba, ano I, n. 2, jul/dez. 2006. Disponível em: $<$ http://intersaberes.grupouninter.com.br/2/arquivos/5.pdf $>$. Acesso em: 4 mar. 2011.

CHARNES, A.; COOPER, W.W.; RHODES, E. Measuring the efficiency of decision-making units. European Journal of Operational Research, v. 2, p. 429-444, 1978.

DANTAS, Marke Geisy da Silva et al. O comportamento do preço das ações de clubes mediante a variação de aspectos contábeis: o estudo de caso do Juventus F.C. - Itália. Revista Ambiente Contábil, Natal, v. 1, n. 2, p. 55-67, 2009. Disponível em: <http://ccsa.ufrn.br/ojs/index.php/ ambiente/article/view/105/95>. Acesso em: 13 Mar. 2011.

DELOITTE FOOTBALL MONEY LEAGUE 2010. Disponível em: <http://www.deloitte. com/assets/Dcom-UnitedKingdom/Local\%20Assets/Documents/Industries/Sports\%20 
Business\%20Group/UK_SBG_DFML2010.pdf>.Acesso em: 12 mai. 2011.

FORBES MOST VALUABLE SOCCER TEAMS 2010. Disponível em: <http://www.forbes. com/lists/2010/34/soccer-10_Soccer-Team-Valuations_Rank.html>.Acesso em: 12 mai. 2011.

GONCALVES, Antonio C. et al. Análise Envoltória de Dados na avaliação de hospitais públicos nas capitais brasileiras. Rev. Saúde Pública [online], v.41, n.3, p. 427-435, 2007. Disponível em: <www.scielo.br/pdf/rsp/nahead/5327.pdf > . Acesso em: 24 mar. 2011.

JAMASB, Tooraj; POLLITT, Michael. International Utility Benchmarking \& Regulation: An Application to European Electricity Distribution Companies. DAE Working Paper, Cambridge n. 115, p. 1-52, Jun. 2002. Disponível em: <http://www.sml.hw.ac.uk/staffpages/tjamasb/ Wp0115.pdf> Acesso em: 11 mar. 2011.

LAMERA, Janice Alves; FIGUEIREDO, Adriano Marcos Rodrigues; ZAVALA, Arturo Zavala. Análise envoltória de dados no estudo da eficiência em assentamentos rurais no estado de Mato Grosso. In: Congresso da SOBER, 49., 2008, Rio Branco. Anais Eletrônicos... Rio Branco: SOBER, 2008. Disponível em: <http://www.sober.org.br/palestra/9/197.pdf>. Acesso em: 4 mar. 2011.

MEZA et al. SIAD - Sistema Integrado de Apoio à Decisão: uma implementação computacional de modelos de análise envoltória de dados. Relatórios de Pesquisa em Engenharia de Produção da UFF, v. 3, p. 20, 2003. Disponível em: <http://www.producao.uff.br/conteudo/rpep/ volume32003/publicacao22003.htm>. Acesso em: 4 mar. 2011.

MELLO et al. Curso de Análise Envoltória de dados. In: SIMPÓSIO BRASILEIRO DE PESQUISA OPERACIONAL. 37., 2005, Gramado. Anais Eletrônicos... Gramado: UFF, 2005. Disponível em: <http://www.uff.br/decisao/sbpo2005_curso.pdf $>$. Acesso em: 25 fev. 2011.

MELO, Clayton Levy Lima de et al. Avaliação do desempenho organizacional: um estudo das companhias do setor elétrico brasileiro com base na Análise Envoltória de Dados (DEA). In: CONGRESSO BRASILEIRO DE CUSTOS, 15., 2008, Curitiba. Anais eletrônicos... Curitiba: ABC,2008. Disponívelem: $<$ http://www.abcustos.org.br/texto/viewpublic?ID_TEXTO=2642>. Acesso em: 4 mar. 2011.

PEREIRA, Carlos Alberto et al. A gestão estratégica de clubes de futebol: uma análise da correlação entre performance esportiva e resultado operacional. . In: CONGRESSO USP DE CONTROLADORIA E CONTABILIDADE, 4., 2004, São Paulo. Anais eletrônicos... São Paulo: Fipecafi, 2004. Disponível em: $<$ http://www.congressousp.fipecafi.org/artigos42004/336. pdf $>$. Acesso em: 4 mar. 2011.

PERRUCI, Felipe Falcone. Clube-empresa: o modelo brasileiro para transformação dos clubes de futebol em sociedades empresárias. Dissertação (Mestrado em Direito) - Curso de Mestrado da Faculdade de Direito Milton Campos, Faculdade de Direito Milton Campos, Nova Lima, 2006. Disponível em: <http://www.mcampos.br/posgraduacao/mestrado/dissertacoes/ felipefalconeperrucci.pdf>. Acesso em: 27 mar. 2011.

RAUPP, Fabiano Maury; BEUREN, Ilse Maria. Metodologia da pesquisa aplicável às Ciências Sociais. In: BEUREN, Ilse Maria (Org.). Como elaborar trabalhos monográficos em São Paulo: Atlas, 2009. P. 76-97. 
REZENDE, Amaury José; PEREIRA, Carlos Alberto. A gestão de contratos de jogadores de futebol: uma análise das decisões identificadas no caso do Clube Atlético Paranaense. In: CONGRESSO INTERNACIONAL DE CUSTOS, 9., 2005, Florianópolis. Anais Eletrônicos... Florianópolis: ABC, 2005. Disponível em: <http://www.abcustos.org.br/texto/viewpublic?ID_ TEXTO=599>. Acesso em: 25 mar. 2011.

RODRIGUES, Marcio Silva; SILVA, Rosimeri Carvalho da. A estrutura empresarial nos clubes de futebol. Revista Organizações \& Sociedade, Salvador, v. 16, n. 48, jan/mar. 2009. Disponível em: <http://www.erevistas.csic.es/ficha_articulo.php?url=oai_revista454:63\&oai_ iden $=$ oai_revista454 $>$. Acesso em: 25 mar. 2011

SANTOS, Ananias Francisco dos. GREUEL, Marcos Alexandre. Análise da gestão financeira e econômica dos clubes brasileiros de futebol: uma aplicação da análise das componentes principais. In: SEMINÁRIOS EM ADMINISTRAÇÃO, 13., 2010, São Paulo. Anais eletrônicos... São Paulo: FEA/USP, 2010. Disponível em: <http://www.ead.fea.usp.br/semead/13semead/ resultado/trabalhosPDF/261.pdf>. Acesso em: 4 mar. 2011.

SILVA, Antônio Carlos Magalhães da; AZEVEDO, Gustavo Henrique W. de . Eficiência e Sobrevivência: Binômio Fundamental para a Previdência Privada Aberta . Revista Brasileira de Risco e Seguro, v. 1, n. 0, p. 68-89, Dezembro de 2004. Disponível em: <http://www.rbrs. com.br/paper/_download/binomio_gustavo.pdf>. Acesso em: 4 mar. 2011.

SILVA, Claudio Vicente Di Gioia Ferreira. Administração esportiva: uma comparação da competitividade do futebol brasileiro com o futebol europeu (G-5) usando métodos quantitativos. 2006. 106 f. Dissertação (Mestrado profissionalizante em Administração) Programa de Pós-graduação e Pesquisa em Administração e Economia, Faculdade de Economia e Finanças IBMEC, Rio de Janeiro. Disponível em: $<$ http://www.ibmecrj.br/sub/RJ/files/ADM_ claudiosilva_nov.pdf $>$. Acesso em: 14 mar. 2011.

; CAMPOS FILHO, Luiz Alberto Nascimento. Gestão de Clubes de Futebol Brasileiros: Fontes Alternativas de Receita. Revista Eletrônica Sistemas \& Gestão, Rio de Janeiro, ano I, v. 1, no 3, p. 195-209, dez. 2006. Disponível em: <http://www.uff.br/sg/index.php/sg/article/ view/SGV1N3A2/20>. Acesso em: 4 mar. 2011 


\section{ENDEREÇO DOS AUTORES}

\section{Marke Geisy Dantas}

Universidade Federal do Rio Grande do Norte, Centro de Ciências Sociais Aplicadas, Departamento de Ciências Contábeis.

Av. Salgado Filho, s/n, Sala 8

Lagoa Nova

59078-900 - Natal, RN - Brasil

\section{Diego Rodrigues Boente}

Universidade Federal do Rio Grande do Norte, Centro de Ciências Sociais Aplicadas, Departamento de Ciências Contábeis.

Av. Salgado Filho, s/n, Sala 8

Lagoa Nova

59078-900 - Natal, RN - Brasil 